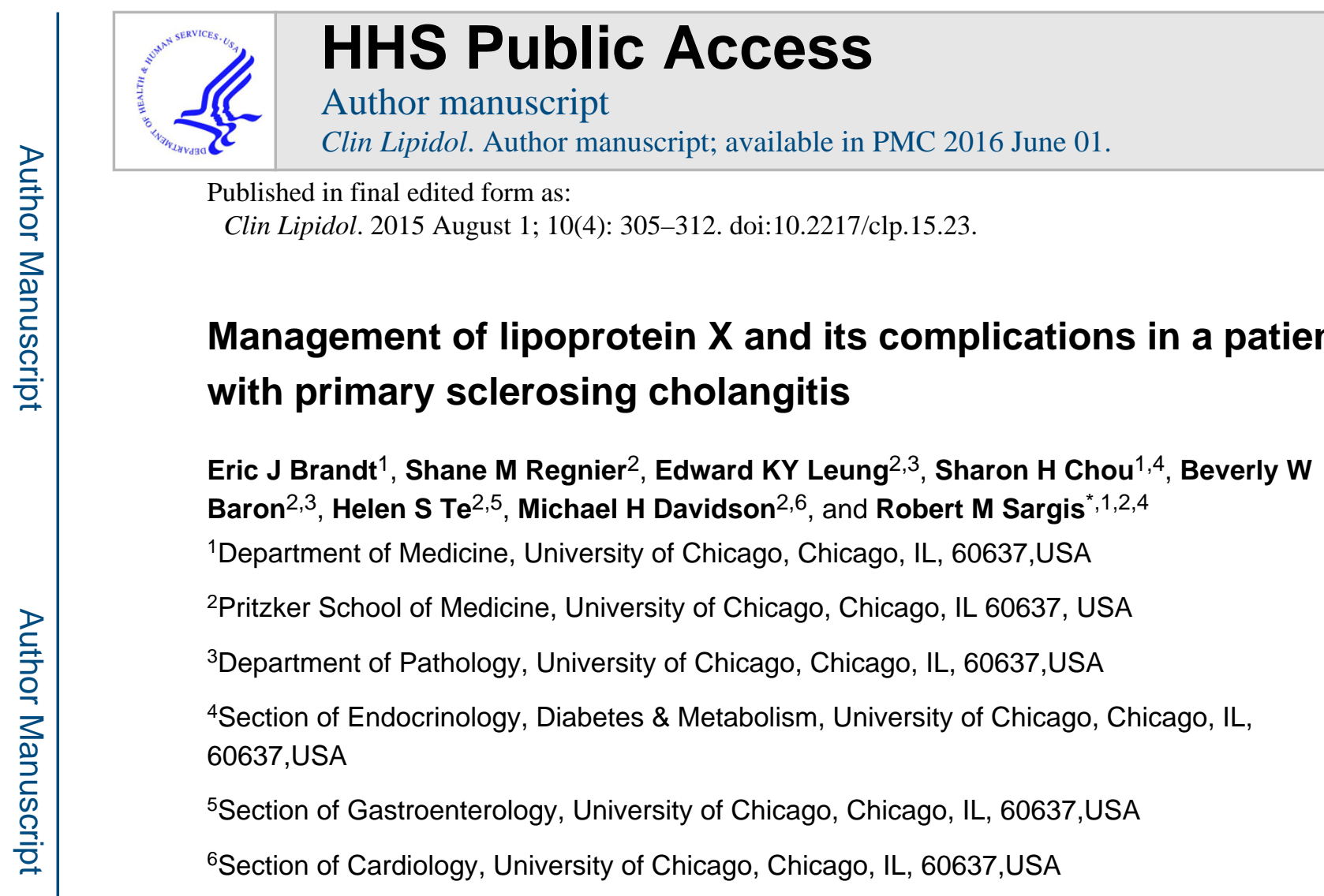

\begin{abstract}
Lipoprotein $\mathrm{X}(\mathrm{LpX})$ is an abnormal lipoprotein found in conditions such as lecithin:cholesterol acyltransferase deficiency and cholestatic states (e.g., primary biliary cirrhosis and primary sclerosing cholangitis). Management of severe hypercholesterolemia due to LpX with drugs and physical removal methods is not well established in the literature. A case is discussed of a 51-yearold woman who presented with multiple electrolyte abnormalities, xanthomas and neuropathy found to be secondary to LpX in the setting of primary sclerosing cholangitis. This case highlights that oral medications, including statins, may be insufficient to normalize lipid levels or improve clinical symptoms of $\mathrm{LpX}$ and presents therapeutic plasma exchange as a safe and effective therapeutic option to treat the morbid sequela of $\mathrm{LpX}$ hyperlipidemia.
\end{abstract}

\title{
Keywords
}

cholestasis; hypercholesterolemia; lipoprotein X; neuropathy; plasma exchange; primary sclerosing cholangitis; statin; xanthoma

\footnotetext{
*Author for correspondence: Tel.: +1 773834 1915, Fax: +1 773834 0851, rsargis@ medicine.bsd.uchicago.edu.

Financial \& competing interests disclosure

The authors have no other relevant affiliations or financial involvement with any organization or entity with a financial interest in or financial conflict with the subject matter or materials discussed in the manuscript apart from those disclosed No writing assistance was utilized in the production of this manuscript.

Informed consent disclosure

The authors state that they have obtained verbal informed consent from the patientfor the inclusion of their medical and treatment history within this case report.
} 


\section{Presentation of case}

\section{Setting \& patient history}

A 51-year-old woman with an 8-year history of primary sclerosing cholangitis (PSC) was referred to our center for consideration of liver transplantation. She was diagnosed with PSC 7 years prior when persistently elevated liver chemistry tests following a cholecystectomy led to an endoscopic retrograde cholangiopancreatography that revealed a common bile duct stricture, dilatation and multiple strictures in the proximal bile ducts, and pruning of the biliary tree. She was initially managed with endoscopic stent placements; however, her liver disease was complicated by progressive cholestasis with serum bilirubin rising from 3 to 7 $\mathrm{mg} / \mathrm{dl}$ and recurrent ascending bacterial cholangitis, prompting referral for liver transplantation. Magnetic resonance imaging of the liver revealed cirrhotic morphology. Other past medical history included ulcerative colitis (moderate histologic activity), depression and vitamin A deficiency. She denied tobacco and substance abuse, and drank only minimal alcohol. Family history was significant for a sister who required bile duct stenting procedure and a brother with hepatomegaly. Medications at the time of referral included ursodeoxycholic acid, mesalamine, sertraline, hydroxyzine, vitamin A and tramadol.

\section{Initial diagnosis \& assessment}

The patient was seen at an outpatient visit during evaluation for potential liver transplantation when she was found to have extreme electrolyte abnormalities, including a sodium of $124 \mathrm{meq} / \mathrm{l}$, potassium of $3.1 \mathrm{meq} / \mathrm{l}$ and chloride of $92 \mathrm{meq} / \mathrm{l}$ (Table 1, column A), prompting hospital admission. The osmolar gap was elevated at $30.7 \mathrm{mOsm} / \mathrm{kg}$, which was explained by severe hypercholesterolemia (total cholesterol [TC] $1484 \mathrm{mg} / \mathrm{dl}$, LDLcholesterol [LDL-C] [by Friedewald formula] 1345 mg/dl, HDL-cholesterol [HDL-C] 31 $\mathrm{mg} / \mathrm{dl}$ and triglycerides $538 \mathrm{mg} / \mathrm{dl}$ ). Electrolytes measured using direct ion selective electrode methodologies were within normal limits, indicating that the initial laboratory abnormalities were spurious (Table 1, column B). At this time, the patient also noted the onset of distal neuropathy symptoms. Additional laboratory evaluation by lipoprotein metabolism profiling confirmed the presence of lipoprotein X (LpX) comigrating with LDL on lipoprotein electrophoresis (Figure 1) and severe lipid abnormalities (Table 2).

\section{Management}

For initial management of $\mathrm{LpX}$, the patient was started on cholestyramine (4 $\mathrm{g}$ twice daily) and pravastatin (20 mg daily), with continuation of ursodeoxycholic acid. Six weeks later, lipid levels were similar (TC 1443 mg/dl, HDL-C 26 mg/dl, LpX/LDL-C [by Friedewald formula] $1359 \mathrm{mg} / \mathrm{dl}$, triglycerides $288 \mathrm{mg} / \mathrm{dl}$ and apolipoprotein B [ApoB] $266 \mathrm{mg} / \mathrm{dl}$ ). The clinical decision was made to transition from pravastatin to rosuvastatin ( $20 \mathrm{mg}$ daily) to increase statin potency in order to further reduce cholesterol biosynthesis. At this time, serum viscosity was slightly elevated ( $2.2 \mathrm{cP}$; normal: $1.4-1.8 \mathrm{cP})$; however, she was asymptomatic. One month later, planar xanthomas emerged on her auricles, nostrils and palmar creases (Figure 2A) with worsening neuropathic pain that interfered with her activities of daily living that was unresponsive to treatment with gabapentin. Despite clinical worsening, laboratory values were somewhat improved (TC $992 \mathrm{mg} / \mathrm{dl}$, HDL-C $30 \mathrm{mg} / \mathrm{dl}$, 
LpX/LDL-C $904 \mathrm{mg} / \mathrm{dl}$, triglycerides $291 \mathrm{mg} / \mathrm{dl}$, ApoB $228 \mathrm{mg} / \mathrm{dl}$ and serum viscosity 1.7 cP). Hepatic function testing did not reveal significant deterioration in hepatic markers (Figure 3B). With worsening clinical symptoms marked by new xanthoma formation and increasing neuropathic pain, medical therapy was deemed to be insufficient, and the decision was made to pursue mechanical correction of her dyslipidemia. Therapeutic plasma exchange (TPE) was chosen as the modality for lipoprotein clearance since other modalities, namely selective LDL apheresis, are more time intensive and were not accessible at our institution. Three TPE sessions were completed. The first two TPE sessions replaced approximately one plasma volume with 5\% albumin, and for the third TPE, 83\% was 5\% albumin and the remainder normal saline. Following completion of TPE, rosuvastatin was increased to $40 \mathrm{mg}$.

\section{Outcome \& implications}

One week after her last TPE completion, lipid levels returned to levels seen 2 years prior to presentation (TC $207 \mathrm{mg} / \mathrm{dl}$, HDL-C $25 \mathrm{mg} / \mathrm{dl}$, LpX/LDL-C $150 \mathrm{mg} / \mathrm{dl}$, triglycerides 160 $\mathrm{mg} / \mathrm{dl}$ ). Four weeks after TPE completion, neuropathic pain and xanthomas resolved (Figure 2B). Lipid values remained stable for 5 months prior to liver transplant (TC 221-252 mg/dl, LpX/LDL-C 149-185 mg/dl). Five months after TPE, orthotopic liver transplantation was performed, and 1-month postsurgery lipid levels were improved despite discontinuation of cholestyramine and rosuvastatin (TC $188 \mathrm{mg} / \mathrm{dl}$, HDL-C $26 \mathrm{mg} / \mathrm{dl}$, LpX/LDL-C $129 \mathrm{mg} / \mathrm{dl}$, triglycerides $163 \mathrm{mg} / \mathrm{dl}$ ). Histology of her native liver confirmed PSC. The temporal relationship between lipid levels and therapeutic interventions are shown in Figure 3A. No treatments, including statins, appreciably worsened hepatic function (Figure 3B).

\section{Discussion}

This case demonstrates marked LpX accumulation in PSC with associated xanthomas, neuropathy, hyperviscosity and spurious electrolyte abnormalities. In the 1940s, suggestions of an abnormal unesterified lipoprotein with slow electrophoretic mobility was noted and later identified as LpX [1,2]. The term LpX was first coined in the literature in 1969 when a unique lipoprotein with similar density to LDL lacking apolipoproteins A and B was identified [3,4]. LpX may appear in conditions such as lecithin:cholesterol acyltransferase (LCAT) deficiency [5], graft versus host disease [6], pregnancy [7] and more commonly, cholestasis $[3,8]$. Given the potential complications arising from LpX accumulation, it is important to consider its presence in each of these clinical situations, especially in states of advanced liver disease with cholestasis where it is most commonly found $[3,8]$. The mechanism underlying LpX accumulation in cholestasis is likely reflux of biliary lipoproteins into the systemic circulation [9]. LCAT deficiency also leads to accumulation of LpX. LCAT is expressed and secreted primarily by the liver and functions in the plasma compartment to catalyze the fatty acid esterification of free cholesterol to form cholesteryl esters, a process important for the maturation of HDL as well as the interconversion of ApoB-containing lipoproteins (i.e., very low density lipoprotein, intermediate density lipoprotein and LDL) [10-12]. Genetic deficiency of LCAT was first described in 1967 and shown to result in low levels of ApoA1 and ApoA2 with increased ApoE, free cholesterol and $\mathrm{LpX}[13,14]$. Because LpX lacks ApoB, this lipoprotein is resistant to hepatic clearance and fails to exert feedback inhibition on cholesterol biosynthesis [15]. 
LpX elevations are quite common in patients with cholestatic liver diseases, occurring in up to $45 \%$ of such patients [16]. While up to $41 \%$ of patients with PSC have been reported to have TC levels greater than the 95th percentile, extreme elevations are less frequently encountered but generate significant therapeutic uncertainty [17]. Severe cholesterol elevations result in artifactual electrolyte abnormalities, xanthomas and hyperviscosity $[18,19]$. In familial LCAT deficiency, LpX is thought to contribute to renal disease due to deposition of LpX in glomeruli [20,21]. It is not yet clear, however, whether LpX confers higher or lower risk for atherosclerosis, although some data indicate the possibility that it has antioxidant activity protecting against LDL modification that could explain the lack of increased risk of atherosclerotic events observed in some cholestatic diseases with abnormal lipoprotein profiles [22].

In the present case, elevated LpX resulting from PSC was associated with hyponatremia as well as intermittent hypokalemia and hypochloremia; in addition, the patient exhibited increased serum viscosity, planar xanthomas on the palms and neuropathic pain leading to the need to more aggressively manage her dyslipidemia. Since LpX is not subject to metabolic regulation and because cholestatic liver disease may be accompanied by hepatocellular injury, management is complex. There is a paucity of information to guide the management of $\mathrm{LpX}$ and its complications. A limited number of case reports have demonstrated the management of cholestatic LpX using several techniques, including mechanical release of biliary obstruction [18], modification of other known obstructive causes (e.g., allograft rejection) [23], lipid apheresis [24] and liver transplantation [25]. For familial LCAT deficiency, low fat, low cal orie diets with high vegetable consumption may reduce kidney damage [26], and low fat diets coupled with angiotensin II receptor blockers may improve renal abnormalities [27]. Additionally, recombinant LCAT transfusion has been shown to significantly improve lipid levels with complete disappearance of immature HDL, increases in mature HDL and increased conversion of cholesterol to cholesteryl esters [28]. The aforementioned treatment options do not, however, present clear management options for patients with cholestatic LpX elevations.

This case presents a multifactorial intervention with statins, cholestyramine, ursodeoxycholic acid and TPE, which markedly reduced cholesterol levels and eliminated xanthomas and neuropathic pain. Inhibition of cholesterol synthesis is an attractive therapeutic target since LpX lacks ApoB, making it resistant to hepatic clearance and ineffective in inhibiting hepatic biosynthesis. However, statin use with coexisting hepatocellular injury may be hazardous. Some studies have demonstrated statin safety in another cholestatic liver disease, primary biliary cirrhosis (PBC), with no evidence of myopathy nor increased serum transaminases [29]. In a retrospective review of 58 patients with PBC, various statins (atorvastatin [28 patients], simvastatin [21 patients, two of whom also received ezetimibe], pravastatin [five patients], fluvastatin [two patients] and rosuvastatin [two patients]) were all well tolerated with no evidence of myalgia or myopathy and no increase in serum alanine aminotransferase levels [29]. In a study of 19 patients with $\mathrm{PBC}$ and LDL-C $>130 \mathrm{mg} / \mathrm{dl}, 48$ weeks of atorvastatin $10 \mathrm{mg}$ was shown to be safe and effective in early stage $\mathrm{PBC}$ [30]. In a randomized study of 21 patients with $\mathrm{PBC}$, simvastatin was specifically shown to safely reduce TC levels relative to placebo at 12 months [31]. In a separate cohort of patients with PBC, simvastatin administration reduced 
serum cholesterol by $34 \%$ in 30 days without adverse events [32]. In the present case, pravastatin followed by rosuvastatin did not appreciably alter liver function studies (Figure 3B). Moreover, after 3-4 months of statin therapy coupled with cholestyramine, TC and LpX/LDL-C levels were somewhat reduced, but with worsening neurological and cutaneous symptoms.

Besides pharmacological therapy, cholesterol levels can be reduced by physical removal. In a previous report of PSC with severe hypercholesterolemia, Franceschini et al. described the use of cascade filtration apheresis to specifically remove small particles within the LDL and LpX size range [24]. However, this technique required weekly to biweekly sessions to reduce TC levels from 1036-1218 to $429 \mathrm{mg} / \mathrm{dl}$ with a total of 15 treatments over 4.5 months [24]. In the present case, TC levels were reduced from 750 to $241 \mathrm{mg} / \mathrm{dl}$ after three weekly TPE treatments with subsequent stabilization of TC levels between 221 and 252 $\mathrm{mg} / \mathrm{dl}$. In the selection of physical removal techniques, it is important to recognize that newer LDL apheresis methods that specifically target ApoB for LDL clearance would not be expected to clear LpX, which lacks ApoB.

A central aspect of our therapeutic approach was the coordinated use of statins, bile acid sequestrants, ursodeoxycholic acid and physical lipoprotein removal. Because cholesterol biosynthesis is upregulated in cholestatic states [33], concomitant statin use may prevent rapid reaccumulation of LpX, thereby improving the durability of short-term physical lipoprotein removal in states of severe hypercholesterolemia. Ursodeoxycholic acid is also employed for lipid management in cholestatic liver disease due to its ability to independently affect cholesterol absorption and bile acid formation from cholesterol precursors [34]. In clinical studies, TC levels were reduced in patients with PSC treated with ursodeoxycholic acid [35]. Moreover, in a later analysis ursodeoxycholic acid-induced reductions in total and LDL cholesterol were shown to correlate with improvements in liver function, suggesting a link between the mechanisms of cholestasis and altered lipid metabolism [36]. In the present case, the contribution of ursodeoxycholic acid to lipid reduction was likely modest since this therapy was initiated prior to development of the marked hypercholesterolemia; however, ursodeoxycholic acid may have facilitated stabilization of cholesterol levels post-TPE. The role for cholestyramine in the treatment of elevated LpX is based on prestatin evidence that cholestyramine reduces LpX in infants with cholestatic liver and biliary tract disease [37]. Here the incremental contribution of cholestyramine in improving or stabilizing cholesterol levels beyond the other interventions (i.e., statin therapy) cannot be fully determined. Finally, patients with PSC often require liver transplantation for definitive therapy. A previous case of PSC demonstrated TC decreasing from 525 to $135 \mathrm{mg} / \mathrm{dl}$ with liver transplantation [25]. In our case, post-transplant lipid levels were also improved relative to pretransplant values despite discontinuation of rosuvastatin and cholestyramine.

Extreme LpX hyperlipidemia can result in additional complications. Spurious laboratory abnormalities resulting from electrolyte exclusion have been reported previously [18]. In this case, the patient was hospitalized in part due to spurious hyponatremia, hypokalemia and hypochloremia. Importantly, the extent of cholesterol interference with many clinical assays is largely unknown since cholesterol interference is not part of routine assay 
validation. This case underscores the need to suspect $\mathrm{LpX}$ as an etiology of electrolyte disturbances in cholestatic liver diseases, prompting measurement of lipid levels when they occur. In addition to false electrolyte abnormalities, extreme elevations in cholesterol levels can result in hyperviscosity syndrome, as previously documented in PBC [19]. For our patient, serum viscosity was only modestly increased with normalization upon cholesterol reduction. Although symptoms of hyperviscosity syndrome were absent in this case, consideration should be given to increased viscosity as a potential contributor to mental status changes in patients with cholestatic liver disease apart from effects mediated by hyperammonemia resulting from coincident hepatocellular injury.

Cutaneous manifestations of various hyperlipidemias include the appearance of xanthomas. Indeed, xanthomas in biliary cirrhosis were described as early as 1938 when links were first drawn between hepatocellular injury in cholestasis and lipoprotein abnormalities [38,39]. Lowering lipid levels can lead to xanthoma regression as demonstrated in a previous case of PSC treated with semi-selective LDL apheresis [24]. In the present case, TPE led to resolution of both the patient's planar xanthomas (Figure 2B) and her neuropathy, suggesting dyslipidemia as their etiology. Interestingly, neuropathic pain preceded the appearance of xanthomas by several months, suggesting that neuropathic pain in patients with cholestatic liver disease may predict emerging dyslipidemia.

While the present case describes the therapeutic benefits of a multimodality approach to the treatment of hypercholesterolemia due to LpX elevation, conclusions from this case should be tempered by its limitations. First, this case report solely describes the management of a single patient with LpX dyslipidemia. Whether this management strategy can be generalized to all patients with cholestatic liver disease requires further investigation. Second, the approach to this patient included multiple pharmacological and mechanical interventions. Whether a more restricted approach (e.g., employing TPE to rapidly clear LpX coupled with statins to limit cholesterol reaccumulation) would be sufficient for effective management of this condition requires direct study. Indeed, much remains to be learned about both the management and the pathophysiology of LpX dyslipidemia. Analyses of larger cohorts that include intensive interrogation of lipoprotein profiling and lipidomics could shed importantly needed light on a condition that remains incompletely understood.

\section{Conclusion}

The present case of severe PSC-associated dyslipidemia due to LpX illustrates the clinical and biochemical complications from LpX-mediated hypercholesterolemia, the need to monitor lipid derangements in patients with cholestatic liver disease, and the coupling of TPE with pharmacological interventions as a management strategy for extreme LpXmediated complications. Application of TPE in this case resulted in significant improvement in clinical symptoms that were not achievable with medical management alone, resulting in significant improvements in symptoms associated with LpX hyperlipidemia prior to definitive treatment with liver transplantation. In the future, clinicians treating patients with LpX-mediated hyperlipidemia with clinical symptoms, including xanthomas, neuropathy or hyperviscosity, should consider TPE as a therapeutic option. 


\section{Acknowledgments}

This work was supported by the NIH (K08-ES019176 to RM Sargis and T32-HD007009 to SM Regnier).

\section{References}

Papers of special note have been highlighted as:

• of interest; $\bullet \bullet$ of considerable interest.

1. Ahrens EH, Kunkel HG. The relationship between serum lipids and skin xanthomata in eighteen patients with primary biliary cirrhosis. J. Clin. Invest. 1949; 28(6 pt 2):1565-1574. [PubMed: 15395959]

2. Kunkel HG, Ahrens EJ. The relationship between serum lipids and the electrophoretic pattern, with particular reference to patients with primary biliary cirrhosis. J. Clin. Invest. 1949; 28(6 pt 2):15751579. [PubMed: 15395960]

3. Seidel D, Alaupovic P, Furman R. A lipoprotein characterizing obstructive jaundice. I. Method for quantitative separation and identification of lipoproteins in jaundiced subjects. J. Clin. Invest. 1969; 48(7):1211-1223. Describes the isolation of a unique fraction of LDL from the plasma of patients with biliary obstruction and coins the term lipoprotein X (LpX). [PubMed: 4978447]

4. Seidel D, Alaupovic P, Furman R, McConathy W. A lipoprotein characterizing obstructive jaundice. II. Isolation and partial characterization of the protein moieties of low density lipoproteins. J. Clin. Invest. 1970; 49(12):2396-2407. [PubMed: 5480863]

5. Torsvik H, Berg K, Magnani HN, McConathy WJ, Alaupovic P, Gjone E. Identification of the abnormal cholestatic lipoprotein (LP-X) in familial lecithin: cholesterol acyltransferase deficiency. FEBS Lett. 1972; 24(2):165-168. [PubMed: 11946663]

6. Turchin A, Wiebe DA, Seely EW, Graham T, Longo W, Soiffer R. Severe hypercholesterolemia mediated by lipoprotein $\mathrm{X}$ in patients with chronic graft-versus-host disease of the liver. Bone Marrow Transpl. 2005; 35(1):85-89.

7. Samsioe G, Johnson P, Gustafson A. Studies in cholestasis of pregnancy. VI. Fatty acid composition of glycerophospholipids before and after delivery. Acta Obstet. Gynecol. Scand. 1977; 56(1):31-35. [PubMed: 842301]

8. Seidel D. Lipoproteins in liver disease. J. Clin. Biochem. 1987; 25(9):541-551.

9. Sörös P, Böttcher J, Maschek H, Selberg O, Müller MJ. Lipoprotein-X in patients with cirrhosis: its relationship to cholestasis and hypercholesterolemia. Hepatology. 1998; 28(5):1199-1205.

[PubMed: 9794902]

10. Nakamura Y, Kotite L, Gan Y, Spencer TA, Fielding CJ, Fielding PE. Molecular mechanism of reverse cholesterol transport: reaction of pre-beta-migrating high-density lipoprotein with plasma lecithin/cholesterol acyltransferase. Biochemistry. 2004; 43(46):14811-14820. [PubMed: 15544352]

11. Jonas A. Lecithin cholesterol acyltransferase. Biochim. Biophys. Acta. 2000; 1529(1-3):245-256. [PubMed: 11111093]

12. Kuivenhoven JA, van Voorst tot Voorst EJ, Wiebusch H, et al. A unique genetic and biochemical presentation of fish-eye disease. J. Clin. Invest. 1995; 96(6):2783-2791. [PubMed: 8675648]

13. Norum KR, Gjone E. Familial serum-cholesterol esterification failure. A new inborn error of metabolism. Biochim. Biophys. Acta. 1967; 144(3):698-700. [PubMed: 6078131]

14. Saeedi R, Li M, Frohlich J. A review on lecithin:cholesterol acyltransferase deficiency. Clin. Biochem. 2014; 48(7-8):474-475. • Provides an excellent review of lecithin:cholesterol acyltransferase deficiency, which is to be included within the differential diagnosis for LpX accumulation.

15. Liersch M, Baggio G, Heuck CC, Seidel D. Effect of lipoprotein-X on hepatic cholesterol synthesis. Atherosclerosis. 1977; 26(4):505-514. [PubMed: 193523]

16. Ross A, Murphy GM, Wilkinson PA, Mills GL, Sherlock S. Occurrence of an abnormal lipoprotein in patients with liver disease. Gut. 1970; 11(12):1035-1037. [PubMed: 5511783] 
17. Jorgensen RA, Lindor KD, Sartin JS, LaRusso NF, Wiesner RH. Serum lipid and fat-soluble vitamin levels in primary sclerosing cholangitis. J. Clin. Gastroenterol. 1995; 20(3):215-219. [PubMed: 7797830]

18. Sivakumar T, Chaidarun S, Lee HK, Cervinski M, Comi R. Multiple lipoprotein and electrolyte laboratory artifacts caused by lipoprotein $\mathrm{X}$ in obstructive biliary cholestasis secondary to pancreatic cancer. J. Clin. Lipidol. 2011; 5(4):324-328. [PubMed: 21784379]

19. Rosenson R, Baker A, Chow M, Hay R. Hyperviscosity syndrome in a hypercholesterolemic patient with primary biliary cirrhosis. Gastroenterology. 1990; 98(5 pt 1):1351-1357. [PubMed: 2323525]

20. Narayanan S. Biochemistry and clinical relevance of lipoprotein X. Ann. Clin. Lab. Sci. 1984; 14(5):371-374. [PubMed: 6476782]

21. Appel, G.; Radhakrishnan, J.; D'agati, V.; Chertow, G. Lecithin-cholesterol acyltransferase deficiency. In: Taal, M.; Marsden, C.; Shorecki, K.; Yu, A.; Brenner, B., editors. Brenner and Rector's The Kidney. Elsevier, Inc.; PA, USA: 2012. p. 1245-1246.

22. Chang P, Lu S, Su T, et al. Lipoprotein-X reduces LDL atherogenicity in primary biliary cirrhosis by preventing LDL oxidation. J. Lipid Res. 2004; 45(11):2116-2122. [PubMed: 15314101]

23. Ooi Y, Mietus-Snyder M, Torres C, Mohan P, Harahsheh A. Lipoprotein-X accumulation: a mimic of familial hypercholesterolemia. Consultant. 2013; 53(5):304-308.

24. Franceschini G, Busnach G, Chiesa G, Sirtori C. Management of lipoprotein-X accumulation in severe cholestasis by semi-selective LDL-apheresis. Am. J. Med. 1991; 90(5):633-8. • This is the first report of the use of semi-selective apheresis techniques to manage a patient with primary sclerosing cholangitis and LpX dyslipidemia with severe xanthomas. [PubMed: 2029022]

25. Gandelman G, Aronow WS, Weiss MB. Resolving hyperlipidemia after liver transplantation in a patient with primary sclerosing cholangitis. Am. J. Ther. 2006; 13(2):171-174. [PubMed: 16645435]

26. Takata K, Kajiyama G, Horiuchi I, Watanabe T, Tokumo H, Hirata Y. A new case of familial lecithin: cholesterol acyltransferase (LCAT) deficiency - paradoxical findings regarding LCAT mass and activity in 23 members of a family. Jpn. J. Med. 1989; 28(6):765-771. [PubMed: 2634146]

27. Naito S, Kamata M, Furuya M, et al. Amelioration of circulating lipoprotein profile and proteinuria in a patient with LCAT deficiency due to a novel mutation (Cys74Tyr) in the lid region of LCAT under a fat-restricted diet and ARB treatment. Atherosclerosis. 2013; 228(1):193-197. [PubMed: 23522979]

28. Simonelli S, Tinti C, Salvini L, et al. Recombinant human LCAT normalizes plasma lipoprotein profile in LCAT deficiency. Biologicals. 2013; 41(6):446-449. [PubMed: 24140107]

29. Abu Rajab M, Kaplan MM. Statins in primary biliary cirrhosis: are they safe? Dig. Dis. Sci. 2010; 55(7):2086-2088. • Reports safety and tolerance of multiple statins in patients with cholestasis due to primary biliary cirrhosis. [PubMed: 19795210]

30. Stojakovic T, Claudel T, Putz-Bankuti C, et al. Low-dose atorvastatin improves dyslipidemia and vascular function in patients with primary biliary cirrhosis after one year of treatment. Atherosclerosis. 2010; 209(1):178-183. [PubMed: 19782361]

31. Cash WJ, O'Neill S, O'Donnell ME, et al. Randomized controlleed trial assessing the effect of simvastatin in primary biliary cirrhosis. Liver Int. 2013; 33(8):1166-1174. [PubMed: 23672463]

32. Del Puppo M, Galli Kienle M, Crosignani A, et al. Cholesterol metabolism in primary biliary cirrhosis during simvastatin and UDCA administration. J. Lipid Res. 2001; 42(3):437-441. • Reports the efficacy of simvastatin at effectively reducing total cholesterol levels in patients with primary biliary cirrhosis. [PubMed: 11254756]

33. Bravo I, Amigo L, Cohen DE, et al. Role of plasma and liver cholesterol- and lipoproteinmetabolism determinants in LpX formation in the mouse. Biochim. Biophys. Acta. 2007; 1770(6): 979-988. [PubMed: 17399905]

34. Miettinen TA, Färkkilä M, Vuoristo M, et al. Serum cholestanol, cholesterol precursors, and plant sterols during placebo-controlled treatment of primary biliary cirrhosis with ursodeoxycholic acid or colchicine. Hepatology. 1995; 21(5):1261-1268. [PubMed: 7737632] 
35. O'Brien CB, Senior JR, Arora-Mirchandani R, Batta AK, Salen G. Ursodeoxycholic acid for the treatment of primary sclerosing cholangitis: a 30-month pilot study. Hepatology. 1991; 14(5):838847. [PubMed: 1937390]

36. Sinakos E, Abbas G, Jorgensen RA, Lindor KD. Serum lipids in primary sclerosing cholangitis. Dig. Liver Dis. 2012; 44(1):44-48. [PubMed: 21890438]

37. Poley J, Caplan D, Magnani H, et al. Quantitative changes of serum lipoprotein-X after cholestyramine administration in infants with cholestatic biliary tract and liver disease. Eur. J. Clin. Invest. 1978; 8(6):397-404. [PubMed: 105912]

38. Thannhauser SJ, Magendantz H. The different clinical groups of xanthomatous diseases; a clinical physiological study of 22 cases. Ann. Intern. Med. 1938; 11(9):1662-1746.

39. Thannhauser S. Serum lipids and their value in diagnosis. N. Engl. J. Med. 1947; 237(14):515522. [PubMed: 20265294] 


\section{Executive summary}

\section{Case presentation}

- Setting and patient history

- 51-year-old woman with an 8-year history of primary sclerosing cholangitis is referred to our center for liver transplant due to progressive disease and recurrent bacterial cholangitis.

- Initial diagnosis and assessment

- The patient was admitted to the hospital after being found to have extreme electrolyte abnormalities. These results were discovered to be spurious and due to lipoprotein $\mathrm{X}(\mathrm{LpX})$ accumulation. She also began to have neuropathic symptoms.

- Management

- The patient continued on ursodeoxycholic acid that was begun prior to referral. Initial management was attempted with statin therapy plus cholestyramine. However, the patient developed palmar xanthomas and worsening neuropathy that interfered with activities of daily living. Mechanical removal via therapeutic plasma exchange (TPE) was initiated with three sessions in total.

- Outcome and implications

- Lipid levels rapidly declined with TPE. Four weeks after the final treatment the patient's xanthomas and neuropathic pain resolved. Lipid levels remained stable on medical management with rosuvastatin and cholestyramine. Liver transplantation occurred 5 months after TPE.

\section{Discussion}

- LpX was initially discovered as a unique fraction of lipoprotein with similar density to LDL.

- $\quad \mathrm{LpX}$ is found in various conditions, including pregnancy, graft-versus-host disease, lecithin:cholesterol acyltransferase deficiency, and more commonly, cholestasis.

- LpX accumulation in biliary cirrhosis is suspected to result from reflux of biliary lipoproteins into the systemic circulation.

- Patients with primary sclerosing cholangitis frequently have hypercholesterolemia, but less frequently experience elevations severe enough to cause clinical symptoms or signs.

- Management of severe LpX dyslipidemia has limited options, but includes medical management, release of biliary obstruction, modification of other obstructive causes (i.e., allograft rejection), lipid apheresis and liver transplantation. 
- Since cholesterol biosynthesis is increased in states of cholestasis, inhibition of cholesterol synthesis is an attractive option for management.

- Statins have been demonstrated to be safe in cholestatic diseases and significantly reduce cholesterol levels.

- Prior case studies showed effective lowering of LpX levels and xanthoma regression with selective lipid apheresis, which required weekly to biweekly treatments.

- Ursodeoxycholic acid and cholestyramine may also facilitate LpX lowering.

- Important findings that occur with LpX hyperlipidemia include spurious laboratory abnormalities, hyperviscosity, xanthoma formation and neuropathy.

\section{Conclusion}

- Application of TPE to severe LpX dyslipidemia improved the lipid profile and clinical symptoms of neuropathy and xanthomas after only a few sessions.

- TPE should be considered as a management option in cases of symptomatic LpX-mediated hyperlipidemia. 


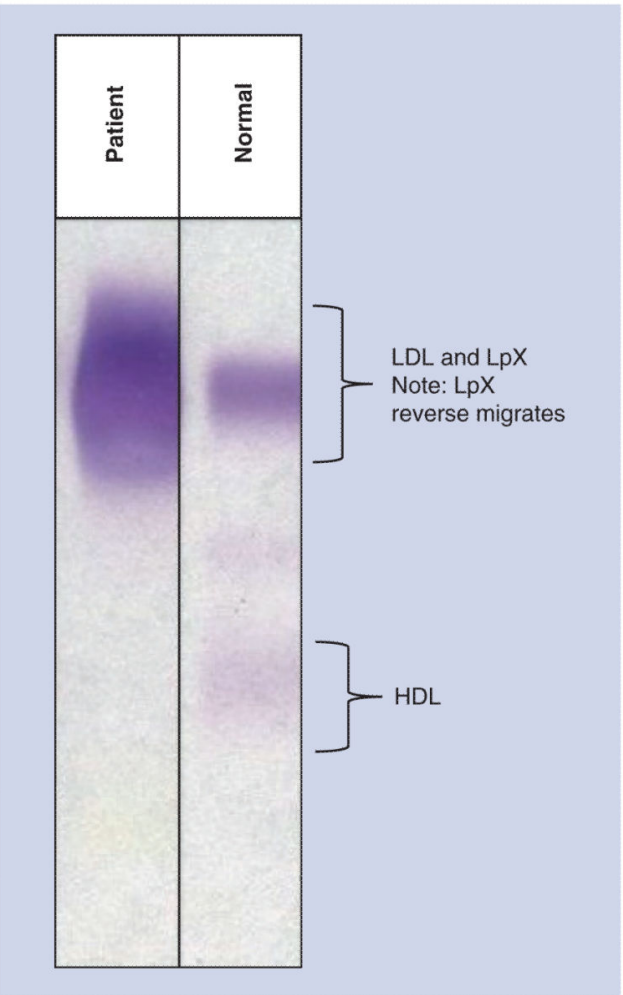

Figure 1. Lipoprotein electrophoresis

Compared with a control sample, the patient's lipoprotein electrophoresis pattern demonstrates the presence of $\mathrm{LpX}$.

LpX: Lipoprotein X. 


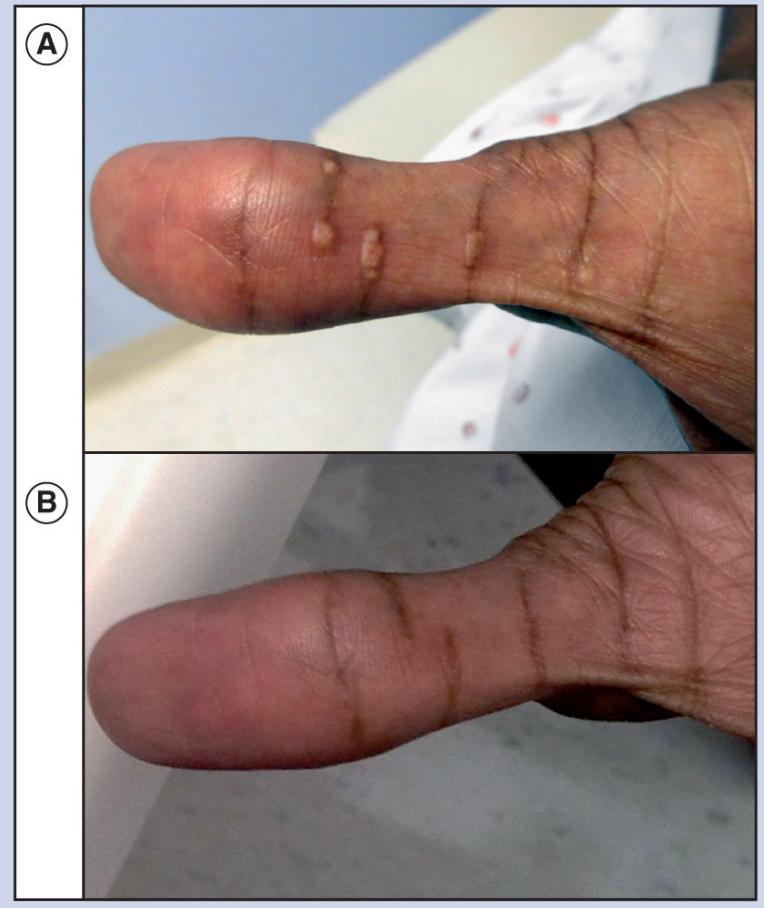

Figure 2. Planar xanthomas of the palms

(A) Planar xanthomas of the hand prior to therapeutic plasma exchange. (B) Resolution of the planar xanthomas that occurred post-therapeutic plasma exchange and that was accompanied by resolution of her neuropathic pain. 


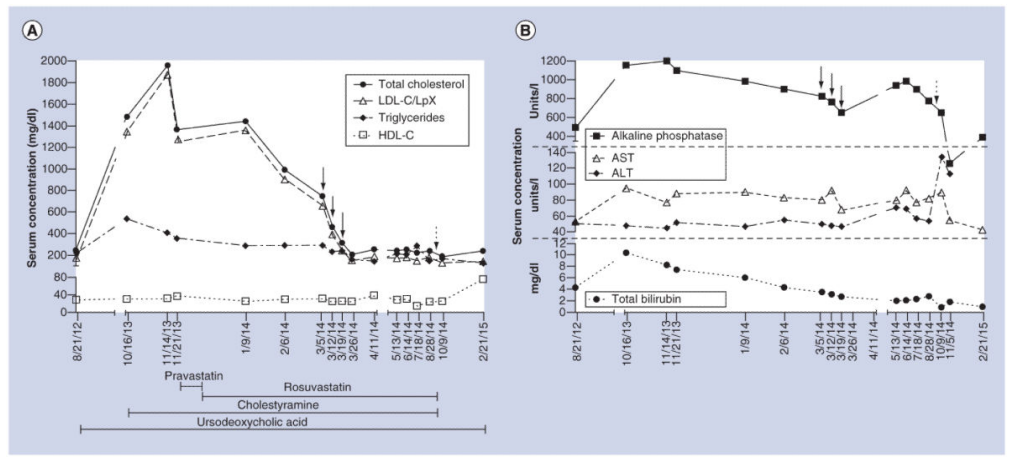

Figure 3. Biochemical response to therapeutic interventions (A) Demonstrates the patient's lipid parameters and their response to therapeutic interventions. (B) Reveals changes in hepatic function studies with lipid-directed interventions. LDL-C concentrations were calculated by the Friedewald equation. Because LpX migrates with LDL, the LDL-C concentration reflects both true LDL-C as well as LpX. Solid arrows indicate occurrences of plasma exchange; dashed arrows indicate liver transplantation.

HDL-C: HDL-cholesterol; LDL-C: LDL-cholesterol; LpX: Lipoprotein X. 


\section{Table 1}

Serum chemistry tests.

\begin{tabular}{|llll|}
\hline Component & Normal range & A & B \\
\hline Glucose & $60-109 \mathrm{mg} / \mathrm{dl}$ & 72 & 91 \\
\hline Sodium & $134-149 \mathrm{meq} / \mathrm{l}$ & $122(\mathrm{~L})$ & 139 \\
\hline Potassium & $3.5-5.0 \mathrm{meq} / \mathrm{l}$ & $3.2(\mathrm{~L})$ & 4.4 \\
\hline Chloride & $95-108 \mathrm{meq} / \mathrm{l}$ & $87(\mathrm{~L})$ & 106 \\
\hline Carbon dioxide & $23-30 \mathrm{meq} / \mathrm{l}$ & $21(\mathrm{~L})$ & $22(\mathrm{~L})$ \\
\hline Anion gap & $6-15 \mathrm{mmol} / \mathrm{l}$ & 14 & 11 \\
\hline BUN & $7-20 \mathrm{mg} / \mathrm{dl}$ & 11 & 10 \\
\hline Creatinine & $0.5-1.4 \mathrm{mg} / \mathrm{dl}$ & 0.6 & 0.7 \\
\hline GFR estimate & $>59 \mathrm{ml} / \mathrm{min} / \mathrm{BSA}$ & 105 & 88 \\
\hline Calcium & $8.4-10.2 \mathrm{mg} / \mathrm{dl}$ & $10.3(\mathrm{H})$ & $10.3(\mathrm{H})$ \\
\hline Total bilirubin & $0.1-1.0 \mathrm{mg} / \mathrm{dl}$ & $8.2(\mathrm{H})$ & $7.4(\mathrm{H})$ \\
\hline Total protein & $6.0-8.3 \mathrm{~g} / \mathrm{dl}$ & 7.0 & 6.9 \\
\hline Albumin & $3.5-5.0 \mathrm{~g} / \mathrm{dl}$ & $3.1(\mathrm{~L})$ & $3.1(\mathrm{~L})$ \\
\hline Alkaline phosphatase & $30-120 \mathrm{U} / 1$ & $1198(\mathrm{H})$ & $1096(\mathrm{H})$ \\
\hline AST & $8-37 \mathrm{U} / 1$ & $77(\mathrm{H})$ & $88(\mathrm{H})$ \\
\hline ALT & $8-35 \mathrm{U} / \mathrm{l}$ & $45(\mathrm{H})$ & $52(\mathrm{H})$ \\
\hline Cholesterol & $120-199 \mathrm{mg} / \mathrm{dl}$ & $1961(\mathrm{H})$ & $1365(\mathrm{H})$ \\
\hline LDL cholesterol & $60-129 \mathrm{mg} / \mathrm{dl}$ & $1848(\mathrm{H})$ & $1257(\mathrm{H})$ \\
\hline HDL cholesterol & $40-80 \mathrm{mg} / \mathrm{dl}$ & $32(\mathrm{~L})$ & $37(\mathrm{~L})$ \\
\hline Triglycerides & $30 \mathrm{mg} / \mathrm{dl}$ & $406(\mathrm{H})$ & $355(\mathrm{H})$ \\
\hline
\end{tabular}

Laboratory values on initial presentation (column A) with electrolytes subsequently measured by direct ion selective electrode methodologies (column B) demonstrate the spurious electrolyte abnormalities due to marked lipid elevations.

BSA: Body surface area; BUN: Blood urea nitrogen; GFR: Glomerular filtration rate; H: High; L: Low.

${ }^{\dagger}$ Calculated by Friedewald formula. 


\section{Table 2}

Serum lipid levels.

\begin{tabular}{|lll|}
\hline Component & Optimal range & Patient \\
\hline Total cholesterol & $<200 \mathrm{mg} / \mathrm{dl}$ & Patient2301 (H) \\
\hline Triglycerides & $<130 \mathrm{mg} / \mathrm{dl}$ & $447(\mathrm{H})$ \\
\hline ApoB & $48-124 \mathrm{mg} / \mathrm{dl}$ & $236(\mathrm{H})$ \\
\hline HDL cholesterol & $\succ 60 \mathrm{mg} / \mathrm{dl}$ & $<3(\mathrm{~L})$ \\
\hline LDL cholesterol & $<110 \mathrm{mg} / \mathrm{dl}$ & $2053(\mathrm{H})$ \\
\hline LDL triglyceride & $50 \mathrm{mg} / \mathrm{dl}$ & $308(\mathrm{H})$ \\
\hline VLDL cholesterol & $<30 \mathrm{mg} / \mathrm{dl}$ & $247(\mathrm{H})$ \\
\hline VLDL triglyceride & $<120 \mathrm{mg} / \mathrm{dl}$ & $138(\mathrm{H})$ \\
\hline$\beta$-VLDL cholesterol & $<15 \mathrm{mg} / \mathrm{dl}$ & Undetectable \\
\hline$\beta$-VLDL triglyceride & $<15 \mathrm{mg} / \mathrm{dl}$ & Undetectable \\
\hline Chylomicron cholesterol & Undetectable & Undetectable \\
\hline Chylomicron triglyceride & Undetectable & Undetectable \\
\hline Lipoprotein(a) & $<3 \mathrm{mg} / \mathrm{dl}$ & $<3$ \\
\hline Lipoprotein X & Undetectable & Present $(\mathrm{H})$ \\
\hline
\end{tabular}

Lipid measurements confirm the presence of lipoprotein $\mathrm{X}$ with associated severe lipid abnormalities in multiple fractions. ApoB: Apolipoprotein B; H: High; L: Low; VLDL: Very LDL. 